\title{
Os efeitos da aplicação dos royalties petrolíferos sobre os investimentos públicos nos municípios brasileiros
}

\author{
Diego Araujo Reis \\ Universidade Federal de Sergipe \\ José Ricardo Santana \\ Universidade Federal de Sergipe
}

\begin{abstract}
A promulgação da Lei oํ 9.478, de 1997, proporcionou um maior ingresso de royalties provenientes da exploração de petróleo e gás natural em alguns municípios brasileiros. Por ser uma receita transitória, é relevante investigar a aplicação desses recursos, da perspectiva das finanças públicas. Este artigo tem como objetivo analisar os efeitos da aplicação dos royalties petrolíferos sobre os investimentos públicos nos municípios brasileiros, no período de 1999 a 2011. A estratégia metodológica envolveu o uso do modelo econométrico de painel, a partir da utilização das variáveis receitas orçamentárias, royalties e despesas de capital dos respectivos municípios, obtidas a partir de fontes secundárias. Os resultados mostram que os municípios mais dependentes dos royalties elevaram as despesas de capital com o aumento dos royalties, tanto pela ótica per capita como pela proporção fiscal.
\end{abstract}

Palavras-chave: royalties; finanças públicas; municípios.

Los efectos de la aplicación de regalías en petróleo sobre inversiones públicas en los municipios brasileños

La promulgación de la Ley 9.478 de 1997 proporcionó una mayor afluencia de regalías (royalty) de petróleo y gas natural en algunos municipios de Brasil. Al ser una receta de transición, es relevante investigar la aplicación de estos recursos desde el punto de vista de las finanzas públicas. Este artículo tiene como objetivo analizar los efectos de la aplicación de las regalías del petróleo en las inversiones públicas en los municipios brasileños en el período 1999-2011. La estrategia consistió en la utilización de un modelo econométrico de panel, a partir de la utilización de los variables ingresos presupuestarios, las regalías y los gastos de capital de los respectivos municipios, obtenidos de fuentes secundarias. Los resultados muestran que los condados más dependientes de regalías se incrementaron los gastos de capital con la entrada de las regalías, tanto por la perspectiva per cápita como la perspectiva fiscal.

Palabras clave: derechos de autor; finanzas públicas; municipios.

DOI: http://dx.doi.org/10.1590/0034-76121815

(cc) BY-NC

Artigo recebido em 30 dez. 2013, e aceito em 4 set. 2014. 
The effects of the application of petroleum royalties on public investments in Brazilian municipalities

The enactment of Law 9.478 of 1997 provided greater inflow of royalties from oil and natural gas in some municipalities of Brazil. Being a transitional revenue, it is relevant to investigate the application of these resources from the perspective of public finances. This article aims to analyze the effects of applying petroleum royalties on public investments in Brazilian municipalities over the period 1999-2011. The methodological procedure involved the use of econometric model of panel, from the use of variable budget revenues, royalties and capital expenditures of the respective municipalities, obtained from secondary sources. The results show that the municipalities who are most dependent of royalties increased capital expenditures with the royalties' growth, both by per capita perspective as the tax rate.

KEYWoRDs: royalties; public finances; municipalities.

\section{Introdução}

Os municípios brasileiros afetados pela exploração de petróleo e gás natural arrecadaram, no período de 1999 a 2011, em valores correntes, cerca de $\mathrm{R} \$ 35,5$ bilhões em royalties petrolíferos (royalties e participações especiais). Essas receitas adicionais têm origem nas transformações ocorridas com a promulgação da Lei no 9.478, de 1997. A soma desses recursos tem um impacto significativo nas finanças públicas, representando uma importante possibilidade de ampliação dos investimentos públicos, no intuito de estimular o desenvolvimento econômico local.

A aplicação dos royalties petrolíferos para viabilizar a ampliação da oferta de bens e serviços é relevante, sobretudo quando se tem em conta que essa é uma condição temporária, decorrente da exploração de recursos naturais não renováveis. Por essa razão, a literatura sobre o tema destaca que a aplicação dos royalties deve buscar potencializar a capacidade da economia local em manter o desenvolvimento quando os recursos tiverem sido exauridos, recomendando como foco a sua utilização em investimento fixo e na formação de recursos humanos. Considerando-se a condição das receitas de royalties, que são incorporados ao orçamento público, assume um papel de destaque o investimento público, enquanto política de desenvolvimento.

No Brasil, a cobrança e a distribuição dos royalties possuem um ordenamento jurídico específico e minucioso. Contudo, a sua aplicação, embora tenha alguns dispositivos legais para nortear as ações de gastos, não está bem definida. Isso faz com que os gestores tenham maior grau de liberdade quanto à sua aplicação. Desse modo, num cenário de elevação das receitas de royalties, é importante analisar a forma de aplicação dos recursos provenientes de royalties pelos entes públicos, sobretudo no que diz respeito à alocação em despesas de capital.

O objetivo geral deste artigo é analisar quais foram os efeitos da aplicação dos royalties sobre as despesas de capital dos entes federativos no período de 1999 a 2011. Foram utilizadas como variáveis as receitas de royalties, as receitas orçamentárias e as despesas de capital, obtidas a partir de fontes secundárias de dados, abrangendo o período de 1999 a 2011, para 
um conjunto de 798 municípios brasileiros. A estratégia metodológica envolveu o uso do modelo econométrico de painel, com segmentação dos municípios, de acordo com a importância dos royalties petrolíferos para as finanças públicas.

O artigo está estruturado em cinco seções incluindo esta introdução. A segunda parte trata da revisão da literatura sobre royalties e desenvolvimento sustentável. Na terceira, são apresentados os procedimentos metodológicos adotados. Na quarta seção são analisados os resultados. A última seção traz as considerações finais.

\section{Royalties e desenvolvimento sustentável: o debate sobre a aplicação dos recursos}

O tema desenvolvimento sustentável é apresentado inicialmente a partir do debate teórico sobre o assunto, situando a discussão sobre a aplicação dos royalties petrolíferos. Em seguida, é abordada a literatura empírica, que traz o modelo utilizado no presente trabalho.

\subsection{Debate teórico sobre desenvolvimento sustentável e papel do investimento público}

Na literatura econômica, a noção de renda esteve ligada inicialmente à propriedade da terra, sintetizada pelos teóricos da renda da terra, sobretudo Ricardo (1996). Para ele, a renda da terra surge porque a terra existe em quantidade limitada e sua qualidade não é uniforme.

Ricardo (1996) explica que, com o crescimento da população, as terras de menor qualidade passam a ser cultivadas, fazendo surgir nas terras de primeira qualidade a renda diferencial. O princípio que se pode extrair é que nas terras de maior qualidade os custos de produção são menores em relação às terras de menor qualidade.

Postali (2002) utiliza esse raciocínio para caracterizar a renda mineral e observa que as reservas minerais também possuem as mesmas características da terra fértil, uma vez que sua oferta pela natureza é limitada. Esse autor alerta para as especificidades da renda mineral, já que sua natureza está ligada, essencialmente, à exauribilidade de sua fonte geradora.

Em face do caráter finito dos recursos não renováveis, Postali (2002) atenta que a extração em um período torna o recurso indisponível em períodos futuros. Esse atributo possibilita pensar a renda mineral por meio do conceito de custo de oportunidade, mais especificamente, o custo de uso.

O custo de uso, ligado à dimensão intertemporal, justificaria a compensação (renda mineral) recebida pelo proprietário de reservas de hidrocarbonetos pela impossibilidade de extrair futuramente o recurso que está sendo retirado atualmente.

Na literatura sobre renda mineral, é reconhecido o trabalho pioneiro de Hotelling (1931), que foi o responsável pela sistematização e incorporação da dimensão temporal. Serra (2005), ao abordar o estudo de Hotelling (1931), descreve que o detentor das reservas de 
minério deve tomar uma decisão sobre duas opções. A primeira opção seria explorar hoje suas jazidas. A segunda opção seria manter a jazida inexplorada. A tomada de decisão de explorar hoje, por sua vez, é explicada pela racionalidade de que os ganhos seriam maiores hoje do que no futuro. Já a opção de manter a reserva mineral inexplorada seria motivada pela perspectiva de obtenção de ganhos mais elevados no futuro.

Postali acrescenta ao debate uma importante reflexão acerca da renda de Hotelling. Já que a extração do minério no presente impossibilita sua extração no futuro, inviabilizando que as gerações futuras usufruam desse recurso, “(...) o que deve ser feito com a renda de Hotelling obtida pelo proprietário do recurso, para não prejudicar os futuros consumidores?" (Postali, 2002:21). Esta indagação envolve uma importante discussão sobre justiça intergeracional e equidade.

Convém destacar, portanto, a contribuição de Hartwick (1977), que investigou a renda mineral à luz da sustentabilidade econômica. Esse autor modelou e reproduziu o funcionamento de uma economia apenas com um recurso não renovável, a qual dependia da própria renda mineral para investimento, visto que não havia poupança. O resultado obtido revelou que, se essa economia investir uma quantidade razoável da renda mineral em bens de capital e capital humano, poderia obter um nível de consumo per capita constante ao longo do tempo.

Nesse contexto, ainda que o trabalho de Hartwick seja apenas uma simplificação da realidade econômica, recebeu grande notoriedade, ficando conhecida sua contribuição como a regra de Hartwick. Essa regra acrescenta ao debate da renda mineral uma importante perspectiva quanto ao tipo de gasto que deve ser realizado a partir do recurso.

É sensato inferir que se deve, portanto, garantir que as gerações futuras usufruam do recurso, mesmo que ele tenha findado. Sua aplicação deve ser de tal modo que os benefícios associados à renda mineral sejam perpetuados de geração a geração. Para tanto, como aponta Hartwick, é necessário investir na diversificação da economia, isto é, em elementos capazes de elevar a produtividade média e garantir maior acumulação de capital para o crescimento econômico. A proposta está baseada no financiamento a atividades mais dependentes de capital humano e capital físico.

Como observado, o desenvolvimento do conceito de renda, principalmente, o de renda mineral, colabora para compreender economicamente a existência de royalties. Além disso, possibilita tratar dos diversos fundamentos desenvolvidos a partir dos teóricos da literatura econômica, que buscam justificar a cobrança de royalties. O tratamento sobre os royalties, especialmente a discussão sobre sua função e significado para o crescimento econômico, é fundamental, à medida que as receitas provenientes desse recurso se elevam.

A literatura econômica advoga que existem circunstâncias nas quais o crescimento da renda per capita não envolve as transformações na sociedade e não resulta, portanto, em desenvolvimento econômico. Este é o caso, por exemplo, dos países ou municípios produtores de petróleo cuja renda per capita não reflete em absoluto o nível de produtividade e de crescimento econômico (Bresser-Pereira, 2008).

Nesse caso, o processo produtivo ocorre em regime de enclave, caracterizado pela "doença holandesa" (Bresser-Pereira, 2008). Essa é uma característica do crescimento econômico 
moderno, cujos benefícios associados ao progresso técnico estariam limitados àquele setor da economia - exploração de recurso natural. Sachs e Warner (1999) já alertavam que países dotados de recursos naturais tendem a crescer com taxas menores do que países onde os recursos naturais são mais escassos.

Bresser-Pereira (2008) explica que as nações que são vítimas da doença holandesa podem ter um aumento transitório da renda per capita, mas que não é suficiente para acomodar as transformações estruturais, culturais e institucionais que são inerentes ao processo de desenvolvimento. Normalmente, nessas economias não se verifica aumento dos padrões de vida da população.

Esse debate tem incorporando cada vez mais o conceito de desenvolvimento sustentável. O desenvolvimento sustentável é imprescindível para a viabilidade da sobrevivência das gerações futuras e da relação entre sociedade e seu meio ambiente de forma equilibrada: "A noção de desenvolvimento sustentável, de tanta importância nos últimos anos, procura vincular estreitamente a temática do crescimento econômico com a do meio ambiente..." (Veiga, 2005:187).

Esse conceito vai além da ideia de desenvolvimento econômico, que é o processo de acumulação de capital e incorporação de progresso técnico ao trabalho e ao capital que leva ao aumento da produtividade, dos salários e do padrão médio de vida da população (BresserPereira, 2008). A concepção de desenvolvimento sustentável é importante por estar associada à ideia de estimular o desenvolvimento econômico no presente, mas com condições de mantêlo no futuro, o que remete à noção de equilíbrio dos benefícios entre gerações.

No processo de estímulo ao desenvolvimento, é fundamental observar o papel dos investimentos públicos, sobretudo quando se consideram os royalties, tendo em vista que estes incidem diretamente sobre a capacidade de gasto do Estado. Levando em conta que o investimento total da economia é realizado pela iniciativa privada e pública, essa instância pode ter um efeito indutor sobre o investimento privado.

A literatura sobre o papel do setor público contempla debates importantes, como no trabalho de Peres (2006), que, tratando de um aspecto mais financeiro, aborda os efeitos dinâmicos dos choques fiscais no período recente. Tratando mais diretamente do papel do investimento público sobre o crescimento, Godoy (2011) analisa as relações de longo prazo entre as variáveis investimento público, produto interno, produtividade total dos fatores e estoque líquido de capital. Seus resultados apontam que 1\% de aumento no investimento público pode aumentar entre $0,24 \%$ e $0,29 \%$ a produtividade total dos fatores da economia brasileira.

Considerando a importância de estimular o investimento público, merecem ser citados trabalhos como os de Montes e Reis (2011) e Bisoto e Afonso (2007). Montes e Reis (2011) tratam da relação entre o investimento, o crescimento e o desenvolvimento destacando a importância dos investimentos em infraestrutura no período de 1995 a 2003 e seus efeitos na economia. Já Bisoto e Afonso (2007) tratam das formas de estímulo ao investimento público no Brasil. Os autores propõem formas de investimento em infraestrutura, pela ação do Estado, sem que seja colocada em risco a responsabilidade fiscal. O debate levanta a perspectiva da 
importância do investimento público para o desenvolvimento, mas na perspectiva de que esse processo seja sustentável, o que tende a ser ainda mais presente quando estão em questão as receitas de royalties.

\subsection{Debate empírico sobre o desenvolvimento sustentável e a aplicação dos royalties}

As abordagens empíricas investigam os efeitos da aplicação de royalties em uma determinada localidade. Na linha defendida por Hartwick (1977), o direcionamento dos royalties para investimento em bens de capital e capital humano possibilitaria às economias altamente dependentes de recursos naturais não renováveis um nível de consumo per capita constante ao longo do tempo. Ou seja, permitiria um equilíbrio na obtenção dos benefícios, uma vez que o desenvolvimento observado na geração atual não comprometeria a situação econômica das gerações futuras.

Contudo, algumas evidências empíricas apresentam países dependentes de recursos naturais que não são capazes de gerar crescimento sustentável. A tese que identifica a particularidade de que economias com abundância em recursos naturais tendem a apresentar taxas de crescimento econômico inferiores às observadas em economias relativamente mais desprovidas é caracterizada na literatura como "maldição dos recursos naturais" — ou simplesmente doença holandesa.

Os estudos, por exemplo, de Rodriguez e Sachs (2004), Postali e Nishijima (2008), Postali (2009) e Nogueira e Menezes (2011) apontaram, a partir dos seus resultados de pesquisa, para a existência desse fenômeno nos países pesquisados. Nesse caso, a análise é feita a partir da observação do impacto dos royalties sobre o PIB.

Rodriguez e Sachs (2004) apresentam um dos motivos para o baixo nível de crescimento das economias dotadas de recursos naturais. Com base no modelo desenvolvido por esses autores, o consumo de superação do estado estacionário de equilíbrio e investimento pode ser ótimo em um modelo de crescimento de Ramsey com os recursos naturais. Portanto, a economia irá convergir para o estado estacionário de cima para baixo, de modo a exibir taxas de crescimento negativas sobre a transição.

As explicações para o péssimo desempenho das economias dependentes de recursos naturais, segundo os demais autores supramencionados, podem estar relacionadas com a má gestão do recurso, ao fato de que a aplicação das rendas obtidas não é direcionada para investimentos em bens de capital e capital humano. Pode também ser justificada pela fragilidade das instituições e pela perda de competitividade, em função do relativo conforto que a renda proporciona.

Postali e Nishijima (2008) avaliaram se os royalties petrolíferos distribuídos na forma da Lei no 9.478, de 1997, contribuíram para melhorar os indicadores sociais dos municípios beneficiados em relação à média nacional. Esses autores estimaram um modelo econométrico de diferenças em diferenças para comparar a evolução dos indicadores sociais dos municípios 
afetados pela nova lei com os não afetados. Usando dados referentes ao período 1991 e 2000, os autores chegaram à conclusão de que os royalties apresentaram efeito marginal negativo nos indicadores da parcela da população com energia elétrica e IDH.

Esse mesmo método foi utilizado por Postali (2009), que avaliou se os royalties distribuídos aos municípios na forma da nova lei contribuíram para o crescimento do PIB destes. Foi comparada a evolução do PIB per capita nos municípios afetados e não afetados pela aprovação da Lei no 9.478. Os resultados mostraram que os municípios beneficiados com royalties petrolíferos cresceram menos do que os municípios que não foram beneficiados por tais recursos. Em geral, para cada 1\% adicional de royalties petrolíferos observa-se uma redução de cerca de $0,06 \%$ na taxa de crescimento do município.

Já Nogueira e Menezes (2011) investigaram os impactos gerados pelas receitas dos royalties petrolíferos sobre o PIB per capita, índices de pobreza e desigualdade nos municípios beneficiados a partir da Lei no $\mathbf{9}$ 9.478. Utilizaram o modelo econométrico de diferenças em diferenças e verificaram que a amostra pode ter passado por um processo mais acelerado de crescimento do PIB per capita, diminuição dos índices de pobreza e desigualdades, antes da implantação da referida lei.

Os resultados desses estudos apontam para a presença da "maldição dos recursos naturais" nas economias beneficiadas, destacando efeitos negativos sobre o crescimento das respectivas localidades. Isto é, as receitas provenientes de royalties não têm gerado maior nível de crescimento do PIB.

O papel do investimento público, como fator de estímulo ao desenvolvimento econômico, aparece na literatura empírica que trata de royalties, em estudos como Nogueira e Santana (2008). Os autores abordam, a partir de um estudo de caso, a relação entre royalties e despesas públicas. Os achados do estudo mostram uma relação pequena entre a elevação das receitas de royalties e o aumento dos investimentos públicos, em um conjunto de municípios sergipanos.

Numa análise que relaciona royalties e as finanças públicas, Bregman (2007) investiga os estados e municípios brasileiros que receberam royalties no período de 1999 a 2005 . Foi analisada empiricamente a relação entre royalties e variáveis selecionadas de despesas públicas. Bregman detectou que os municípios mais dependentes de royalties petrolíferos estariam alocando maior parte desse recurso às despesas de capital, o que apontaria para efeitos favoráveis do uso dos royalties. Por outro lado, os municípios e os estados de dependência intermediária estão destinando a maior parte desses recursos às despesas correntes.

Os estudos apresentados analisam a utilização dos royalties, destacando-se a abordagem do desenvolvimento sustentável, na perspectiva dos impactos da aplicação desses recursos sobre as gerações futuras. Os estudos investigam especialmente a relação dos royalties com indicadores de desenvolvimento e finanças públicas. Considerando que, pelo marco legal vigente no Brasil, os royalties são inseridos no orçamento público, torna-se de fundamental importância a análise sobre a forma como tais recursos são aplicados pelos entes governamentais. A abordagem dos trabalhos que tratam dessa literatura serve de base para a formatação dos procedimentos empíricos utilizados no presente trabalho. 


\section{Estratégia metodológica para análise dos efeitos da aplicação dos royalties}

A metodologia utilizada está voltada à investigação das possíveis relações entre os royalties arrecadados pelas municipalidades e suas despesas públicas de capital, no período compreendido entre 1999 e 2011. Inicialmente são apresentados os indicadores utilizados na análise. Em seguida, é abordado o modelo econométrico e a estratégia de estimação. Na sequência, apresenta-se a composição da amostra e a segmentação dos grupos de análise.

\subsection{Indicadores de dependência e indicadores de despesa pública}

A metodologia utilizada adotou dois indicadores de dependência e dois indicadores de despesa de capital. O enfoque desta investigação é o contraste entre os indicadores de dependência e os de despesa pública de capital de modo a analisar os efeitos dos royalties petrolíferos nos municípios pesquisados.

O primeiro indicador de dependência são os Royalties Per Capita (RPC), descritos pela razão entre os royalties e participações especiais (PE) recebidos pelo município (i), em determinado ano (t) e a estimativa da população da localidade (i) no mesmo ano (t). O RPC é uma medida dada em valores monetários. A expressão é dada a seguir:

$$
\text { RPC i,t }=\frac{(\text { Royalties }+ \text { PE)i,t }}{(\text { População)i,t }}
$$

Já o segundo indicador de dependência, definido pela relação entre Royalties e Receita Orçamentária (RRO), é descrito pela razão entre a soma dos Royalties e Participações Especiais (PE) recebidas pelo município (i) em determinado ano (t) e a receita orçamentária anual do município (i) no ano (t). O RRO é um índice orçamentário que proporciona saber o percentual de participação dos royalties petrolíferos na receita orçamentária do respectivo município. A expressão é dada a seguir:

$$
\mathrm{RRO} i, \mathrm{t}=\frac{(\text { Royalties }+P E) i, t}{(\text { Receita Orçamentária }) i, t}
$$

Por conseguinte, apontam-se as variáveis de despesa pública de capital, essenciais para o contraste com RPC e RRO. Os dois indicadores são: Peso das Despesas de Capital (PDK) e Despesa de Capital Per Capita (DKPC); eles são descritos pela razão entre a Despesa de Capital efetuada pelo município (i), em determinado ano (t), e a Despesa Orçamentária executada pela localidade (ou a estimativa da população da localidade) (i) no ano (t). As expressões são dadas a seguir: 


$$
\begin{aligned}
\text { PDK } \mathrm{i}, \mathrm{t} & =\frac{(\text { Despesa de Capital)i,t }}{(\text { Despesa Orçamentária) } i, t} \\
\text { DKPC } \mathrm{i}, \mathrm{t} & =\frac{(\text { Despesa de Capital)i,t }}{(\text { População)i,t }}
\end{aligned}
$$

O PDK mede a proporção das despesas de capital (investimentos, inversões financeiras e amortização da dívida) sobre a despesa orçamentária. O DKPC mede os gastos per capita de capital. Sustenta-se que, quanto maior a proporção de PDK e DKPC, mais elevada é a probabilidade de o município obter ganhos futuros. Isso porque um maior nível de despesa de capital pode resultar num maior acúmulo de capital por trabalhador, aumentando a produtividade da mão de obra, razão pela qual as economias se diferenciam.

A despeito da classificação possibilitada por esses indicadores, Bregman (2007) explica que mensurar a dependência das finanças municipais em relação aos royalties petrolíferos exige cautela, visto que o dinamismo econômico do ente beneficiado pode interferir na sua dependência em relação aos royalties petrolíferos. Assim, aqueles municípios que possuem baixo dinamismo econômico em termos de geração de produto serão mais dependentes das receitas de royalties. De forma contrária, os municípios de alto dinamismo econômico tendem a ter menor dependência.

\subsection{Modelo de análise}

Para a avaliação empírica da aplicação dos royalties petrolíferos, à luz das finanças públicas, foi utilizado um modelo econométrico, com dados em painel, calculado pelo Stata 12. A referência é o estudo de Bregman (2007). O modelo investiga a relação entre os indicadores de dependência (RRO e RPC), utilizados como variáveis explicativas, e os indicadores de despesas públicas (em proporção da despesa total, PDK, ou em valores per capita, DKPC), a partir de equações específicas. Nos modelos, foi incluída uma dummy, no intuito de captar o efeito da crise financeira do subprime, ocorrida no final da década anterior. A estimação foi realizada a partir das equações abaixo:

$$
\begin{aligned}
& P D K_{i t}=\beta_{0}+\beta_{1} R R O_{i t}+\delta_{0} D_{t}+\alpha_{i}+\varepsilon_{i t} \\
& D K P C_{i t}=\beta_{0}+\beta_{1} R P C_{i t}+\delta_{0} D_{t}+\alpha_{i}+\varepsilon_{i t}
\end{aligned}
$$

Onde $i$ se refere aos municípios da amostra e $t$ corresponde ao período de tempo. $\mathrm{O}$ estimador $\beta_{0}$ corresponde ao intercepto da equação, $\beta_{1}$ capta o efeito da variável explicativa sobre a variável dependente, $\delta_{0}$ capta o efeito da variável dummy de tempo, $\alpha_{i}$ é um parâmetro que capta efeitos específicos não observados em cada município e $\varepsilon_{i t}$ é o termo de 
erro idiossincrático. Para cada município supõe-se a existência de características individuais não observáveis, representadas pelo termo $a_{i}$. Esses efeitos específicos serão tratados ou como variável aleatória ou como efeitos fixos, estimados no modelo.

Se $\alpha_{i}$ for um parâmetro fixo no tempo para cada município, $\operatorname{com} \varepsilon_{i t} \sim \operatorname{IID}\left(0, s_{e}^{2}\right)$ e os regressores independentes de $\varepsilon_{i t}$, tem-se o modelo de efeitos fixos. Nesse caso, não se assume independência entre as variáveis explicativas e o efeito não observável dos indivíduos. A estimação pelo modelo de efeitos aleatórios, que supõe a inexistência de correlação entre os efeitos individuais e os regressores, seria inconsistente (Baltagi, 2005). Na presença de efeitos fixos as estimativas são calculadas a partir das diferenças dentro de cada município ao longo do tempo, considerando-se então a estatística $\mathrm{R}^{2}$ dentro do grupo. No caso dos efeitos aleatórios, toma-se o $\mathrm{R}^{2}$ total, que considera variação não só intra como também intergrupos (Forbes, 2000). A aplicação do teste de Hausman permite detectar se há presença de efeitos fixos ou aleatórios. Uma abordagem aplicada dessa metodologia pode ser encontrada ainda em Santana, Garcia e Souza (2005).

A análise do sinal do coeficiente de inclinação $(\beta)$ possibilita avaliar essas relações, verificando se os resultados estão em conformidade com o que preceituam os fundamentos teóricos que norteiam a aplicação dos royalties. Em relação à dummy de tempo, espera-se um efeito de depreciação na equação, tendo em vista que representa um momento de crise.

No caso da equação (1), espera-se que a relação entre RRO e o indicador de despesa de capital PDK seja positiva. Ou seja, uma maior disponibilidade de royalties, em relação à receita orçamentária (RRO), no município deveria ocasionar um aumento no investimento público, representado pelo peso da despesa de capital no orçamento municipal (PDK).

No caso da equação (2) espera-se que a relação entre o RPC e o indicador de despesa per capita DKPC seja também positiva. Ou seja, uma maior disponibilidade de royalties por habitante (RPC) deveria gerar um aumento na despesa de capital por habitante (DKPC).

A utilização do modelo com dados em painel, combinando dados de corte transversal e de séries temporais, permite o controle da heterogeneidade presente nos grupos de dependência, formados ao longo do estudo. O uso dos dados em painel possibilita controlar os efeitos das variáveis não observadas, uma vez que cada município possui características específicas que influenciam suas despesas públicas (Duarte, Lamounier e Takamatsu, 2007).

Em relação aos estimadores, foi avaliado o teste t, para verificar se a variável explicativa apresentava algum efeito na variável explicada, o que se deduz a partir da capacidade de rejeitar a hipótese nula, de que o parâmetro é zero, considerando os níveis de significância de $1 \%, 5 \%$ ou $10 \%$.

Como a característica marcante do método de dados em painel é a combinação de dados em séries temporais e em corte transversal, sua estimação está susceptível a violações de pressupostos típicos de dados em corte transversal (heterocedasticidade) e em séries temporais (autocorrelação de primeira ordem). Por essa razão, foram realizados testes, com o objetivo de detectar se houve violação das hipóteses de homocedasticidade e de não existência de autocorrelação.

Para a verificação de presença de homocedasticidade dos resíduos em painel foi utiliza- 
do o teste Wald. A homocedasticidade entre as unidades do corte transversal é a hipótese nula desse teste. Assim, valores de "p" inferiores a 5\% indicam rejeição da hipótese nula, indicando a presença de heterocedasticidade. No presente trabalho, todas as estimativas rejeitaram a hipótese nula.

Quanto à investigação da autocorrelação de primeira ordem, utilizou-se o teste de Wooldridge. Esse teste utiliza a primeira defasagem dos resíduos da regressão. A hipótese nula do teste de Wooldridge é de não existência de autocorrelação. Dessa maneira, nas situações em que o valor "p" for inferior a 5\%, deve-se rejeitar essa hipótese, o que implica dizer que o pressuposto foi violado. Como será visto nos resultados, apenas uma regressão não rejeitou a hipótese nula para o teste de Wooldridge.

Para os testes que rejeitaram a hipótese nula da homocedasticidade na presença de efeitos fixos foi necessário corrigir a estrutura da matriz de variância-covariância dos erros. Para tanto, foi utilizado o método Feasible Generalized Least Squares (FGLS), ou Mínimos Quadrados Generalizados Factíveis. A vantagem desse método é que ele permite corrigir a heterocedasticidade e a autocorrelação de primeira ordem (caso seja identificada), gerando coeficientes eficientes e erros-padrão não viesados. Como se tratam de estimativas que sofrem efeitos fixos, com vistas a controlar os efeitos fixos no método FGLS foram inseridas dummies de intercepto para os municípios.

Em se tratando da ocorrência da heterocedasticidade e autocorrelação de primeira ordem no modelo de efeitos aleatórios, foram utilizados dois métodos adicionais, a saber: a estimação robusta da matriz de covariância ${ }^{1}$ e a estimação com efeitos aleatórios, em processo autorregressivo de primeira ordem - AR (1).

O método efeitos aleatórios em processo AR (1), por sua vez, é utilizado para a autocorrelação de primeira ordem na presença de efeitos aleatórios. Ele consiste em estimar um único parâmetro de autocorrelação para todos os municípios, em detrimento de graus de liberdade da estimativa. E a estimação robusta da matriz de covariância consiste em ajustar os erros-padrão, supondo que a variância muda para cada município, sendo, portanto, útil para corrigir a heterocedasticidade (Wooldridge, 2013).

\subsection{Amostra e segmentação dos grupos}

Para a realização do estudo, foram utilizados dados dos municípios brasileiros que receberam royalties, no período de 1999 e 2011 . A coleta de dados acerca dos royalties, das participações especiais e da população foi oriunda do sistema info royalties (Ucam, 2012). Foram utilizados dados em valores reais. ${ }^{2}$ Para o cálculo do RRO, foram utilizados os dados de finanças públicas da série Finanças do Brasil (Finbra) (STN, 2012).

A amostra abrange 798 municípios e um espaço temporal de 13 observações anuais

\footnotetext{
${ }^{1}$ Esse procedimento para correção dos desvios padrões é apontado por Greene (2000).

${ }^{2}$ Foi utilizado o deflator implícito do PIB para deflacionar os valores dos RPC e DKPC.
} 
para cada município. A composição da amostra levou em consideração as limitações quanto à disponibilidade de dados para os municípios, tendo em vista que, no período completo de tempo, o município nem sempre havia recebido royalties, de acordo com a base info royalties, ou não dispunha de informações fiscais, de acordo com a base Finbra. Desse modo, trabalhouse com um painel não balanceado de dados.

Na construção da amostra, considerando as limitações de dados, buscou-se preservar o maior número de municípios possível. Nesse sentido, o procedimento levou em consideração os seguintes critérios para inclusão do município:

1) ter sido beneficiário de royalties ou participação especial em pelo menos oito anos, do total de 13 anos disponíveis na base info royalties, no período de 1999 e 2011;

2) possuir ao menos três orçamentos disponíveis na STN, do total de 13 anos disponíveis na base Finbra, no período de 1999 a 2011.

Com base nesses critérios obteve-se uma amostra de municípios onde foi possível proceder à comparação dos agregados orçamentários dos entes, onde constam as variáveis de despesa, com os royalties petrolíferos. Assim, dos 1.031 municípios identificados como beneficiados por royalties, no período em análise, a amostra reduziu-se para 798 municípios, mesmo considerando dados não balanceados.

Para segmentar a amostra, foram utilizados os indicadores de dependência. Bregman (2007) salienta que a utilização de dois indicadores (RPC e RRO) justifica-se pela tentativa de separar os municípios que apresentam elevado dinamismo econômico daqueles com baixo dinamismo.

Cada município deverá apresentar um valor de referência de royalties per capita (RPC) e da relação entre royalties e receita orçamentária (RRO) para a composição dos grupos, que serão representados por suas médias nos anos investigados. O primeiro critério utilizado para a formação dos grupos de dependência foi o de RPC. O valor mediano desse indicador definiu o corte entre os municípios, formando dois grupos: alto RPC e baixo RPC (quadro 1).

Quadro 1

Brasil: grupos de municípios

\begin{tabular}{|ccccc|}
\hline $\begin{array}{l}\text { Número de } \\
\text { Municípios }\end{array}$ & RPC & $\begin{array}{c}\text { Número de } \\
\text { Municípios }\end{array}$ & RRO & $\begin{array}{c}\text { Número de } \\
\text { Municípios }\end{array}$ \\
\hline & Altos RPC: Grupos 1 e 2 & 399 & Baixo RRO: Grupo 1 & 200 \\
798 & Baixo RPC: Grupos 3 e 4 & 399 & Alto RRO: Grupo 2 & 199 \\
\cline { 2 - 6 } & & & Baixo RRO: Grupo 3 & 200 \\
& & & Alto RRO: Grupo 4 & 199 \\
\hline
\end{tabular}

Fonte: Elaborado pelos autores, a partir da metodologia proposta por Bregman (2007). 
Do mesmo modo foram organizados os grupos de RRO. Dentro de cada um dos dois grupos de RPC, foi encontrada a média do RRO, de forma a subdividi-los, montando um total de quatro grupos, como apresentado no quadro 1 :

v Grupo 1: alto RPC - baixo RRO, agrega municípios com alto volume de royalties por habitante, com pequena importância desse componente na receita arrecadada pelo município;

v Grupo 2: alto RPC - Alto RRO, agrega municípios com alto volume de royalties por habitante, com grande importância desse componente na receita arrecadada pelo município;

v Grupo 3: baixo RPC - baixo RRO, agrega municípios com baixo volume de royalties por habitante, com pequena importância desse componente na receita arrecadada pelo município;

v Grupo 4: baixos RPC - Alto RRO, agrega municípios com alto volume de royalties por habitante, com grande importância desse componente na receita arrecadada pelo município.

É importante mencionar que os 798 municípios que se enquadraram nos requisitos receberam, em valores reais, cerca de $\mathrm{R} \$ 47,7$ bilhões. A segmentação por grupos permitiu manter o foco do estudo voltado àqueles municípios nos quais a receita de royalties é importante na composição das finanças públicas.

\section{Análise de resultados}

A análise das possíveis relações entre os royalties e despesas públicas de capital dos entes municipais é apresentada em duas etapas. Inicialmente, é feita uma abordagem a partir da análise descritiva das variáveis, com foco nos indicadores de dependência e nos indicadores de despesa de capital. Em seguida, são analisados os resultados do modelo econométrico sobre os efeitos da aplicação de royalties petrolíferos em nível municipal. Os resultados são apresentados a partir da segmentação dos grupos de municípios.

\subsection{Análise descritiva das variáveis}

A avaliação dos indicadores de royalties e das contas municipais agregadas nos grupos de municípios, além de permitir constatar a heterogeneidade entre estes, possibilita traçar as características que distinguem os grupos em termos fiscais. Essa análise preliminar busca auxiliar na interpretação da investigação econométrica que será feita posteriormente.

Como mostra a tabela 1, são 798 municípios beneficiários de royalties, distribuídos por 15 estados brasileiros. O Grupo 1 é formado em sua maioria pelos municípios potiguares, capixabas e sergipanos. Em relação ao Grupo 2, é destacada a presença dos municípios do Rio de Janeiro, que representam 35\% do grupo, contando ainda com municípios capixabas, 
sergipanos, potiguares e baianos. No Grupo 3 a composição está concentrada pelos 147 municípios baianos, além de 37 municípios paulistas. Quanto ao Grupo 4, o destaque vai para os 67 municípios cearenses, tendo ainda a presença de municípios alagoanos, baianos, paranaenses e paulistas.

Em relação aos dados gerais sobre a arrecadação nos grupos de dependência, o Grupo 2 possui disparadamente a maior parcela dos royalties arrecadados. Dos $\mathrm{R} \$ 47,7$ bilhões em forma de royalties petrolíferos arrecadados pelos municípios, no período de 1999 a 2011, o Grupo 2 angariou mais de 96\%, isto é, cerca de R\$ 45,8 bilhões. O Grupo 1 ocupa o segundo lugar, com uma participação de 3,34\% do total de royalties petrolíferos, o que equivale a $\mathrm{R} \$ 1,6$ bilhão. No que diz respeito aos Grupos 3 e 4, estes possuem uma pequena fatia de participação, com $0,49 \%$ e 0,09\%, respectivamente. Juntos, equivalem a cerca de $\mathrm{R} \$ 273,2$ milhões.

Tabela 1

Composição dos grupos de dependência

\begin{tabular}{|crrrrr|}
\hline Estados & Grupo 1 & Grupo 2 & Grupo 3 & Grupo 4 & Total \\
\hline AL & 4 & 9 & 7 & 32 & 52 \\
AP & 1 & 0 & 1 & 1 & 3 \\
AM & 9 & 1 & 1 & 7 & 18 \\
BA & 5 & 19 & 147 & 25 & 196 \\
CE & 3 & 9 & 1 & 67 & 80 \\
ES & 45 & 31 & 0 & 1 & 77 \\
PA & 9 & 0 & 1 & 7 & 17 \\
PR & 8 & 3 & 5 & 20 & 36 \\
PE & 0 & 1 & 0 & 0 & 1 \\
RJ & 3 & 70 & 0 & 0 & 73 \\
RN & 69 & 20 & 0 & 3 & 92 \\
RS & 2 & 4 & 0 & 1 & 7 \\
SC & 1 & 5 & 0 & 0 & 6 \\
SP & 3 & 6 & 37 & 19 & 65 \\
SE & 38 & 21 & 0 & 16 & 75 \\
Total & 200 & 199 & 199 & 798 \\
\hline
\end{tabular}

Fonte: Elaborada pelos autores.

Outro dado importante para a caracterização dos municípios beneficiários é o número de habitantes. Os municípios nos quatros grupos tinham, em 2011, cerca de 65,8 milhões de habitantes. O Grupo 3 era o de maior contingente populacional, com cerca de 27,8 milhões de habitantes, seguido do Grupo 1, com 14,1 milhões. O Grupo 2 era o de menor população, ao passo que apresentava a maior taxa de crescimento médio populacional, com 1,02\%, no período de 1999 a 2011. 
Em relação aos dados fiscais dos grupos de municípios, devem ser destacadas as informações sobre as receitas e despesas orçamentárias agregadas, que permitem avaliar a dimensão do volume das economias públicas municipais, conforme evidencia a tabela 2 .

Tabela 2

Valor global das receitas e despesas nos grupos de municípios, 1999 a 2011 (R\$ bilhões) ${ }^{1}$

\begin{tabular}{|lrrrr|}
\hline Contas & Grupo 1 & Grupo 2 & Grupo 3 & Grupo 4 \\
\hline Receita Orçamentária & 307,69 & 236,73 & 634,45 & 172,62 \\
Despesa Orçamentária & 299,22 & 230,23 & 624,62 & 170,51 \\
Despesas de Capital & 43,63 & 30,71 & 78,61 & 19,91 \\
\hline
\end{tabular}

Fonte: Elaborada pelos autores.

Nota: (1) Valores em R\$ bilhões corrigidos pelo deflator implícito do PIB (ano base 2011).

Constata-se que o grupo 3 é o que possui maior volume fiscal. Um dos motivos que explicam a magnitude desses valores é a presença dos municípios paulistas nesse grupo. O Grupo 1 ocupa o segundo lugar em termos de valores de receitas e despesas orçamentárias. O Grupo 2, caracterizado pelo recebimento de muitos royalties petrolíferos e por um baixo dinamismo, apresenta uma receita orçamentária total de $\mathrm{R} \$ 236$ bilhões e uma despesa orçamentária de R\$ 230 bilhões, no período 1999 a 2011.

A observação das despesas de capital, colocadas como razão da despesa orçamentária, sinaliza para o comportamento do investimento público nos respectivos grupos de municípios. Os grupos mostram percentuais próximos de investimento, superiores a $11 \%$, com destaque para os grupos 1 e 2, que correspondem àqueles municípios que mais receberam royalties nesse período. Os resultados mostram o Grupo 1 com um percentual de 14,58\%, o Grupo 2 com 13,34\%, o Grupo 3 com 12,58\% e o Grupo 4 com 11,68\%.

O diagnóstico preliminar da situação financeira nos grupos de municípios, assim como a evolução dos indicadores de despesas ao longo do tempo, embora forneçam indicações sobre o quadro das finanças públicas, devem ser observados com cautela, posto que o comportamento dos municípios que compõem os grupos varia em função do estágio de desenvolvimento de cada ente.

\subsubsection{Análise descritiva a partir dos indicadores de dependência}

Em adição à análise descrita acima, é importante avaliar os valores médios dos indicadores de dependência dentro dos grupos de municípios, no período de 1999 a 2011 (figura 1). Do ponto de vista global dos resultados médios, percebe-se que os royalties per capita (RPC) fo-

ram de $\mathrm{R} \$ 108,36$, enquanto a razão entre royalties e receita orçamentária (RRO) alcançou o percentual de $3,54 \%$. 
No Grupo 1, de alto dinamismo econômico, observou-se um RPC médio de R\$12,20 e uma média de $0,71 \%$ de suas receitas dependentes de royalties petrolíferos. No Grupo 2 , composto por municípios que receberam muitos royalties petrolíferos, verificou-se o maior RPC médio, R\$ 419,39, sendo o RRO igual a 12,92\%. Para o Grupo 3, formado pelos municípios que auferem poucos royalties petrolíferos e apresentam alto dinamismo, observa-se que estes exibem a menor média de RPC entre os grupos ( $\mathrm{R} \$ 0,34)$ e o menor valor médio de RRO $(0,03 \%)$. Já no Grupo 4, que recebe poucos royalties petrolíferos e apresenta baixo dinamismo econômico, o RPC médio foi de R\$ 1,51e RRO de 0,15\%.

Ao longo do período de 1999 a 2011, como mostra a figura 1, verifica-se que, em média, os RPCs dos grupos elevaram-se, com exceção de 2009 que foi marcado pela redução da produção de petróleo. Mesmo assim, a taxa de crescimento médio do RPC foi positiva para todos os grupos no período.

Assim, para além da baixa taxa de crescimento populacional, o aumento do volume de royalties petrolíferos é decisivo para o efeito incremental médio anual do RPC no Grupo 2, atingindo um valor superior a $\mathrm{R} \$$ 600,00, em 2011 (figura 1). No que tange aos demais grupos, os valores médios de RPC são consideravelmente baixos, uma vez que a arrecadação é bem menor, sobretudo nos grupos 3 e 4 .

Figura 1

Evolução do RPC nos grupos de dependência (1999 a 2011)

Evolução do RPC médio Grupo 1

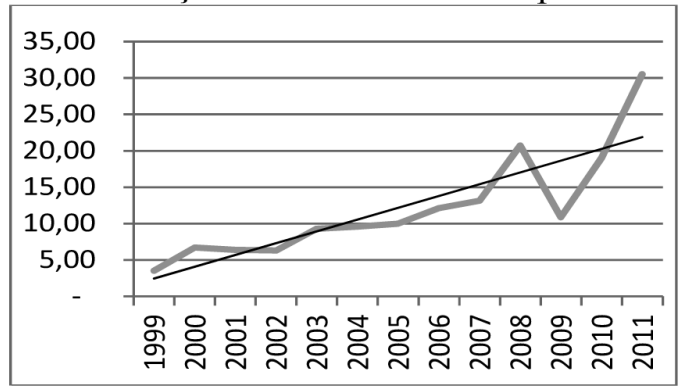

Evolução do RPC médio Grupo 3

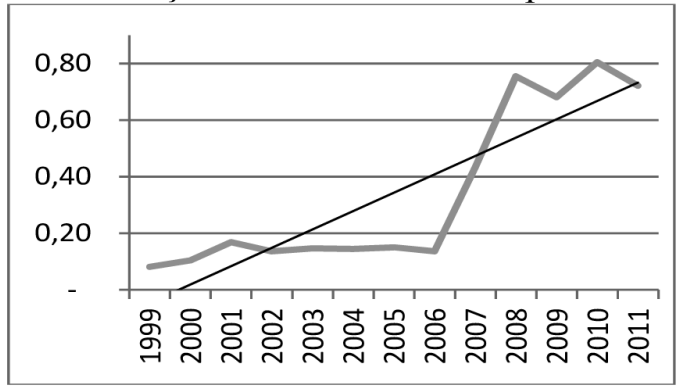

Evolução do RPC médio Grupo 2

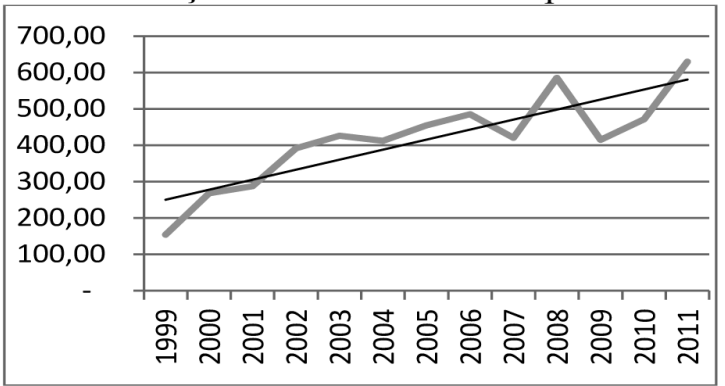

Evolução do RPC médio Grupo 4

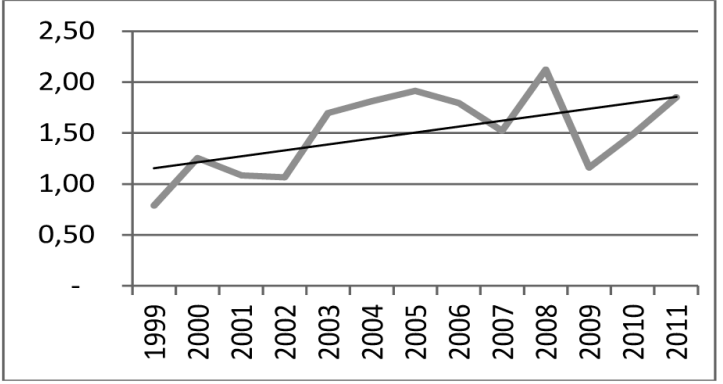

Fonte: Elaborado pelos autores. Valores em R\$. 
Pela ótica da dependência dos orçamentos municipais em relação às receitas de royalties dentro dos quatro grupos (figura 2), verifica-se que o comportamento é bastante oscilante, já que o orçamento público está sujeito a um número maior de variáveis que determinam a magnitude de sua formação. Não obstante, a taxa de crescimento médio do RRO foi positiva para todos os grupos. Em média, o Grupo 2 exibe maior dependência em relação ao peso dos royalties sobre sua receita orçamentária, estando sua dependência acima de $11 \%$ a partir de 2000.

\section{Figura 2}

Evolução do RRO nos grupos de dependência (1999 a 2011)

Evolução do RRO médio Grupo 1

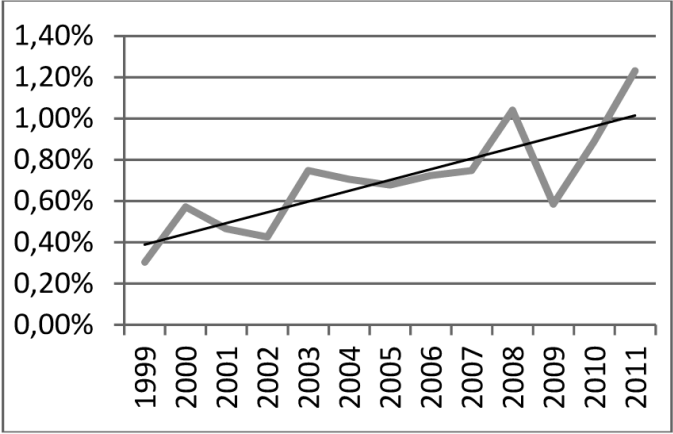

Evolução do RRO médio Grupo 3

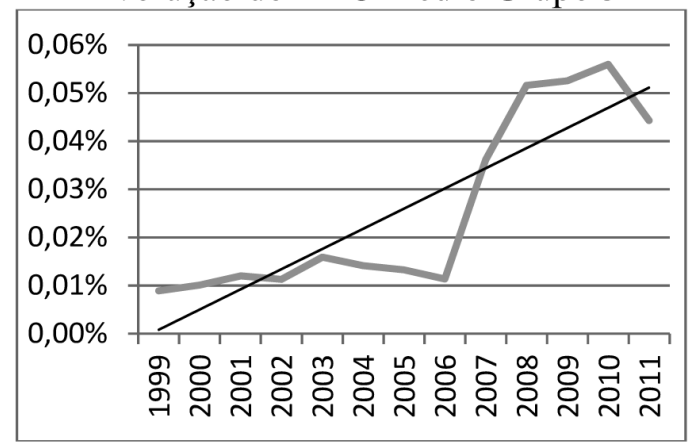

Evolução do RRO médio Grupo 2

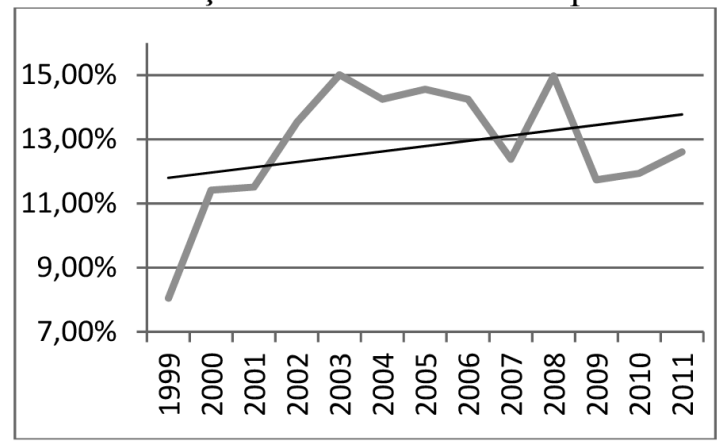

Evolução do RRO médio Grupo 4

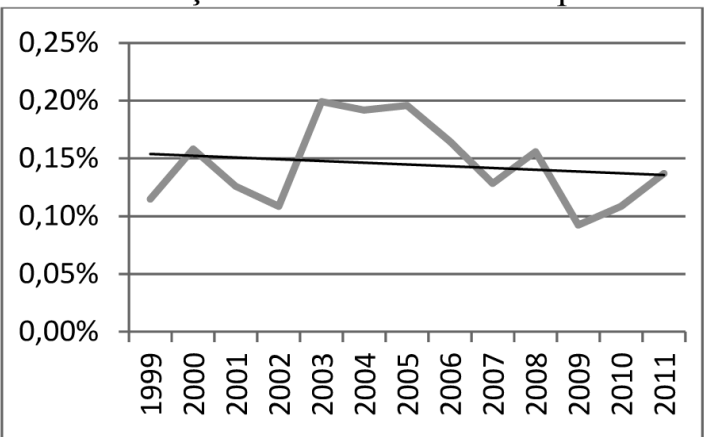

Fonte: Elaborado pelos autores.

Os Grupos 1 e 3, ainda que mostrem valores médios de RRO relativamente baixos, apresentam uma trajetória de ampliação da dependência, seja pela redução dos demais componentes de receitas, seja pela ampliação da arrecadação dos benefícios associados às rendas petrolíferas. Quanto ao Grupo 4, isto é, os municípios que recebem poucos royalties petrolíferos e apresentam baixo dinamismo econômico, estes exibem uma redução em média na dependência em relação aos recursos provenientes de royalties. Essa diminuição também está 
sinalizada para os municípios do Grupo 2, a partir de 2003, embora com oscilações ao longo do período.

\subsubsection{Análise descritiva a partir dos indicadores de despesa de capital}

Em complemento à análise acima, é importante avaliar a composição média funcional da despesa de capital dentro dos grupos de municípios. Em consequência da magnitude dos orçamentos do Grupo 3, estes também obtiveram os maiores patamares de despesas de capital em valores absolutos (tabela 3 ).

A tabela 3 discrimina as despesas de capital para comparação entre os grupos no período de 1999 a 2011. Deve-se mencionar que esses resultados também devem ser avaliados com cautela, já que os valores absolutos não sugerem verificar em que proporção os gastos foram efetuados.

Tabela 3

Brasil: médias observadas dos indicadores de despesas dentro dos grupos (1999 a 2011$)^{3}$

\begin{tabular}{|crrrr|}
\hline Indicadores de Despesas & Grupo 1 & Grupo 2 & Grupo 3 & Grupo 4 \\
\hline PDK (\%) & 12,14 & 13,29 & 11,43 & 12,44 \\
DKPC (R\$) & 192,41 & 297,06 & 141,58 & 148,21 \\
\hline
\end{tabular}

Fonte: Elaborado pelos autores.

Para o primeiro indicador, Peso das Despesas de Capital (PDK), verifica-se que a proporção da despesa média com capital é maior no Grupo 2, que efetuou 13,29\% em proporção de suas despesas totais.

Pela ótica dos indicadores de despesas per capita, ver-se-á que a distribuição das médias se altera consideravelmente entre os grupos de municípios. O Grupo 2 exibe os maiores valores de Despesa de Capital Per Capita (DKPC). Assim, ressalta-se que os Grupos 1 e 2 se diferenciam dos demais pelo alto valor de RPC para a formação dos grupos de municípios, o que também é válido para os resultados dos indicadores de despesas per capita.

Como forma de complementar a análise acima, será observado o comportamento dos indicadores de despesa (percentuais e per capita) nos respectivos grupos de municípios. $\mathrm{O}$ primeiro a ser verificado é o PDK, conforme a figura 3, que apresenta os valores médios nos quatro grupos.

\footnotetext{
${ }^{3}$ Os valores encontrados na tabela 2 foram calculados pela média das observações das respectivas variáveis anuais dos municípios, dentro de cada grupo.
} 
Verifica-se que há uma tendência declinante do peso das despesas de capital nos grupos. Essa tendência é confirmada pela taxa média de crescimento negativa obtida por todos os grupos, especialmente os Grupos 3 e 4, com -1,84\% e -1,37\%, respectivamente.

No entanto, o Grupo 1 apresenta a menor inclinação em relação aos demais grupos, com a taxa negativa de crescimento médio de $-0,05 \%$, sendo que o Grupo 2 exibe a segunda menor inclinação com taxa negativa de $-0,80 \% \%$. Identificam-se ainda nos Grupos 1 e 2 os menores valores de dispersão em relação à média.

\section{Figura 3}

Evolução do PDK nos grupos de dependência (1999 a 2011)
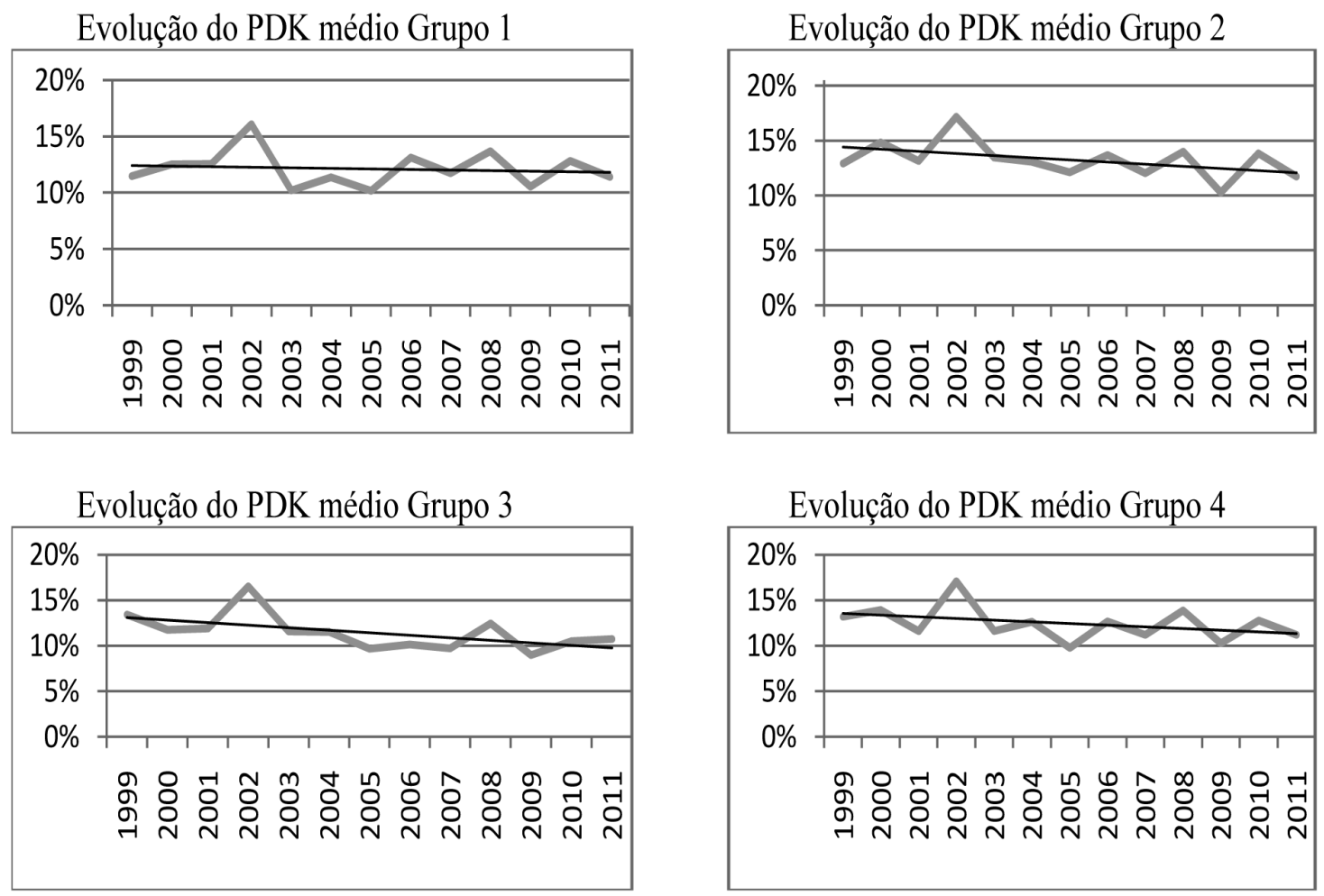

Fonte: Elaborado pelos autores.

Constata-se também que o comportamento do PDK entre os grupos segue trajetória oscilante parecida, o que aponta para fatores em comum na determinação da PDK. É válido mencionar que o RRO apresentou uma tendência de elevação para os Grupos 1, 2 e 3, quando se considera o comportamento entre o início e o final do período. De modo geral, desconsiderando a magnitude dos valores, o comportamento do PDK contrasta inversamente com RRO, 
quando observada a trajetória dos valores de referência médios dos grupos de dependência, com exceção do Grupo 4.

Cabe observar que no período de 2008 a 2010, marcado inicialmente pelos altos valores arrecadados em forma de royalties petrolíferos e depois pela acentuada queda de arrecadação, o valor médio do PDK apresenta comportamento semelhante à trajetória do RRO, principalmente nos Grupos 1 e 2. No caso do Grupo 2, como mencionado, a tendência de queda no RRO pode ser observada a partir de 2003, embora com algumas oscilações.

Figura 4

Evolução do DKPC nos grupos de dependência (1999 a 2011)

Evolução do DKPC médio Grupo 1

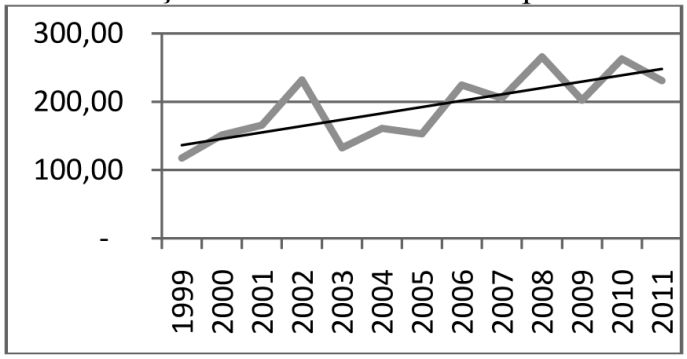

Evolução do DKPC médio Grupo 3

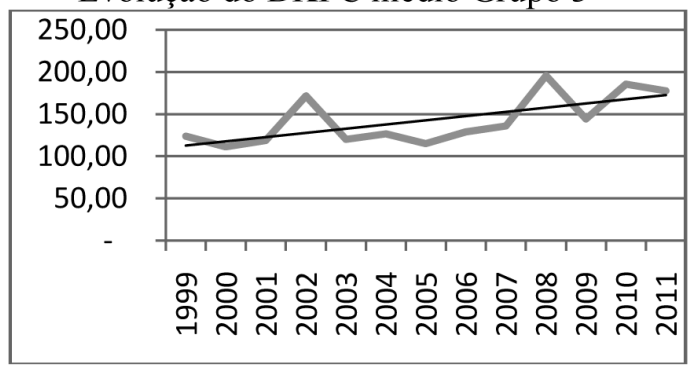

Evolução do DKPC médio Grupo 2

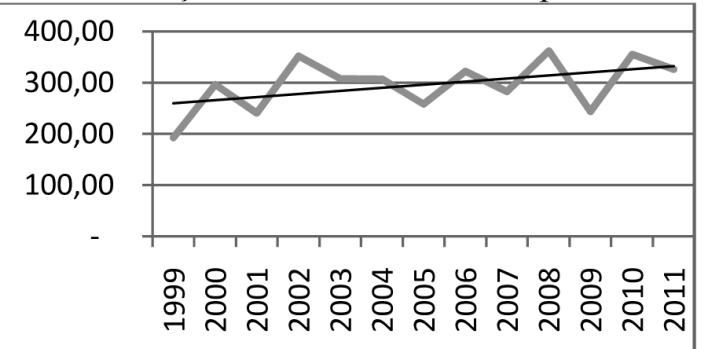

Evolução do DKPC médio Grupo 4

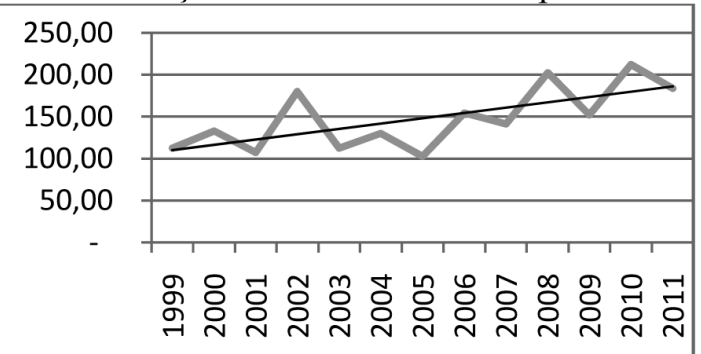

Fonte: Elaborada pelos autores. Nota: Valores em R\$.

Pela ótica per capita (figura 4), o indicador DKPC médio, nos grupos de dependência, mostra uma trajetória de crescimento no período. As taxas de crescimento médio foram positivas. As maiores taxas foram obtidas pelos Grupos 1 e 2, com 5,78\% e 4,51\%, respectivamente. Os Grupos 3 e 4 obtiveram taxas médias de crescimento no período, de 3,06\% e 4,16\%, respectivamente. Conforme já constatado, pela média no período, o Grupo 2 é o que exibe maiores valores médios per capita de despesas de capital e maiores taxas de dispersão em relação a sua média, seguido pelo Grupo 1 .

A partir dos dados apresentados, cabem duas observações. A primeira é que os municípios estão elevando seus gastos médios per capita em capital per capita, sobretudo os 
municípios dos Grupos 2 e 1, de grande RPC. A segunda refere-se aos efeitos dinâmicos das populações, que podem determinar essa proporção, já que o número de habitantes é variável fundamental no denominador.

Deste modo, pode-se extrair da comparação entre os valores médios de PDK e DKPC que, embora as despesas de capital estejam reduzindo sua participação na proporção das despesas orçamentárias, o volume dessas mesmas despesas por habitantes está se elevando.

\subsection{Análise dos resultados das estimativas do modelo}

A utilização do modelo econométrico de regressão tem o objetivo de analisar a relação de causalidade entre os royalties petrolíferos e as despesas de capital, no conjunto de municípios brasileiros, a partir das equações (5) e (6).

As tabelas 4 e 5 mostram os procedimentos realizados para a determinação do modelo a ser utilizado. Conforme a apresentação da metodologia do trabalho, foram realizados os seguintes testes: Hausman, Wald (heterocedasticidade) e Wooldridge (Autocorrelação). Portanto, a heterogeneidade observada ou não observada dos municípios será incorporada por meio do modelo de efeitos aleatórios ou efeitos fixos, respectivamente. O teste de Hausman, para a escolha entre o modelo de efeitos aleatórios e o modelo de efeitos fixos. De acordo com as tabelas 4 e 5 , foram especificados cinco modelos com efeitos aleatórios e três modelos com efeitos fixos.

No que se refere aos testes de Wald e Wooldridge, registra-se a presença destas duas categorias de distúrbios nas tabelas 4 e 5. Entretanto, na Tabela 5, o grupo (2) não apresentou autocorrelação de primeira ordem nos distúrbios. Para corrigir a estrutura dos erros nos modelos foram adotados três métodos de estimação diferentes, já caracterizados na metodologia: FGLS, EA-AR(1) e ERMC.

Tabela 4

Brasil: testes e método de correção utilizados nas estimativas da relação entre PDK e RRO na equação (5), para os grupos de municípios, 1999-2011

\begin{tabular}{|ccccc|}
\hline \multirow{2}{*}{$\begin{array}{c}\text { Testes e métodos de } \\
\text { correção }\end{array}$} & Grupo (1) & Grupo (2) & Grupo (3) & Grupo (4) \\
\cline { 2 - 5 } & Efeitos Aleatórios & Efeitos Aleatórios & Efeitos Aleatórios & Efeitos Aleatórios \\
\hline Hausman (Prob>chi2) & 0,59 & 0,94 & 0,36 & 0,44 \\
Wald (Prob>chi2) & 0,00 & 0,00 & 0,00 & 0,00 \\
Wooldridge (Prob>F) & 0,00 & 0,00 & 0,00 & 0,04 \\
Método de Correção & EA-AR(1) e ERMC & EA-AR(1) e ERMC & EA-AR(1) e ERMC & EA-AR(1) e ERMC \\
\hline
\end{tabular}

Fonte: Elaborada pelos autores. 
Tabela 5

Brasil: testes e método de correção utilizados nas estimativas da relação entre DKPC e RPC, na equação (6), para os grupos de municípios, 1999-2011

\begin{tabular}{|ccccc|}
\hline \multirow{2}{*}{ Testes e métodos de correção } & Grupo (1) & Grupo (2) & Grupo (3) & Grupo (4) \\
\cline { 2 - 5 } & Efeitos Fixos & Efeitos Fixos & Efeitos Fixos & Efeitos Aleatórios \\
\hline Hausman (Prob>chi2) & 0,00 & 0,00 & 0,00 & 0,13 \\
Wald (Prob>chi2) & 0,00 & 0,00 & 0,00 & 0,00 \\
Wooldridge (Prob>F) & 0,03 & 0,29 & 0,01 & 0,02 \\
Método de Correção & FGLS & FGLS & FGLS & EA-AR(1) e ERMC \\
\hline
\end{tabular}

Fonte: Elaborada pelos autores.

Na presença de efeitos fixos, foi usado o FGLS. E na presença de efeitos aleatórios, foram utilizados o EA-AR(1) e o ERMC. Quando detectada a ocorrência de heterocedasticidade no modelo de efeitos aleatórios, os desvios-padrão foram estimados pelo método ERMC. Nesse caso, os resultados são apresentados nas tabelas 6 e 7. O EA-AR(1) foi utilizado para a correção da autocorrelação de primeira ordem nas estimativas do modelo de efeitos aleatórios. Essas estimações são apresentadas nas tabelas 8 e 9.

Tabela 6

Brasil: estimativas da relação entre PDK e RRO na equação (5), para os grupos de municípios, 1999-2011

\begin{tabular}{|ccccc|}
\hline $\begin{array}{c}\text { Peso da Despesa de } \\
\text { Capital (PDK) }\end{array}$ & Grupo (1) & Grupo (2) & Grupo (3) & Grupo (4) \\
\cline { 2 - 5 } RRO & Efeitos Aleatórios & Efeitos Aleatórios & Efeitos Aleatórios & Efeitos Aleatórios \\
\hline Dummy 2009 & 0,0407 & $0,1456^{* * *}$ & $-31,3413^{* * *}$ & $-5,3229^{* * *}$ \\
& $-0,0153^{* * *}$ & $(0,0302)$ & $(4,3559)$ & $(1,4624)$ \\
№ de Observações & $(0,0041)$ & $-0,0304^{* * *}$ & $-0,0174^{* * *}$ & $-0,02495^{* * *}$ \\
Procedimento & 2346 & $(0,0040)$ & $(0,0039)$ & $(0,0040)$ \\
\end{tabular}

Fonte: Elaboração própria.

Nota: Os números entre parênteses representam, nos estimadores, o valor do desvio-padrão (dp). Significativos a 1\% (***), a 5\% (**) e a $10 \%(*)$. 
Tabela 7

Brasil: estimativas da relação entre DKPC e RPC, na equação (6), para os grupos de municípios, 1999-2011

\begin{tabular}{|ccccc|}
\hline \multirow{2}{*}{$\begin{array}{c}\text { Despesa de Capital Per Capita } \\
\text { (DKPC) }\end{array}$} & Grupo (1) & Grupo (2) & Grupo (3) & Grupo (4) \\
\cline { 2 - 5 } & Efeitos Fixos & Efeitos Fixos & Efeitos Fixos & Efeitos Aleatórios \\
\hline RRO & $1,7506^{* * *}$ & $0,2271^{* * *}$ & $17,5296^{* * *}$ & $3,0851^{*}$ \\
& $(0,1422)$ & $(0,0130)$ & $(2,4313)$ & $(1,8654)$ \\
Dummy 2009 & $-3,2530$ & $-14,1770^{* *}$ & $-18,0910^{* * *}$ & 6,4883 \\
& $(4,0160)$ & $(5,5815)$ & $(2,7082)$ & $(9,0809)$ \\
№ de Observações & 2332 & 2273 & 2349 & 2265 \\
Procedimento & FGLS & FGLS & FGLS & ERMC \\
\hline
\end{tabular}

Fonte: Elaboração própria.

Nota: Os números entre parênteses representam, nos estimadores, o valor do desvio-padrão (dp). Significativos a 1\% (***), a 5\% (**) e a $10 \%(*)$.

As tabelas 8 e 9 mostram os resultados das estimações corrigidas para os quatro grupos de municípios. Em cada tabela, constam quatro estimativas entre as respectivas variáveis explicativas de royalties e as variáveis dependentes de despesas, sendo adicionada uma dummy de tempo (ano 2009) com vistas a captar o efeito da crise financeira do subprime sobre as estimativas, que pode afetar as relações desejadas. Portanto, serão apresentados os valores dos coeficientes de inclinação encontrados para a variável independente e para a dummy 2009, seguidos de seus respectivos desvios-padrão.

A tabela 8 traz os resultados das estimativas da equação (5), que investiga a relação entre a proporção das receitas de royalties sobre a receita orçamentária (RRO) e o investimento público, representado pelo peso das despesas de capital em relação às despesas orçamentárias (PDK).

Tabela 8

Brasil: estimativas da relação entre PDK e RRO na equação (5), para os grupos de municípios, 1999-2011

\begin{tabular}{|ccccc|}
\hline $\begin{array}{c}\text { Peso da Despesa de Capi- } \\
\text { tal (PDK) }\end{array}$ & Grupo (1) & Grupo (2) & Grupo (3) & Grupo (4) \\
\cline { 2 - 5 } & Efeitos Aleatórios & Efeitos Aleatórios & Efeitos Aleatórios & Efeitos Aleatórios \\
\hline RRO & $-0,0727$ & $0,1409^{* * *}$ & $-30,0805^{* * *}$ & $-5,0479 * * *$ \\
& $(0,2077)$ & $(0,0179)$ & $(4,2307)$ & $(1,1794)$ \\
Dummy 2009 & $-0,0190^{* * *}$ & $-0,0311^{* * *}$ & $-0,0190^{* * *}$ & $-0,0270^{* * *}$ \\
& $(0,0043)$ & $(0,0043)$ & $(0,0034)$ & $(0,0043)$ \\
№ de Observações & 2346 & 2280 & 2350 & 2274 \\
Procedimento & EA-AR(1) & EA-AR(1) & EA-AR(1) & EA-AR(1) \\
\hline
\end{tabular}

Fonte: Elaboração própria.

Nota: Os números entre parênteses representam, nos estimadores, o valor do desvio-padrão (dp). Significativos a 1\% (***), a 5\% (**) e a $10 \%(*)$. 
Nos dados apresentados a partir da tabela 8, apenas os municípios classificados no Grupo 2 apresentaram relação significativa e positiva entre a receita de royalties (RRO) e as despesas de capital (PDK), confirmando o que seria esperado. Assim, os municípios que possuem alta dependência de royalties têm alocado o recurso para as despesas de capital. Já nos municípios do Grupo 1 não há relação significativa que permita inferir sobre seu coeficiente de RRO. Quanto aos municípios dos Grupos 3 e 4, os coeficientes estimados são negativos e significativos, apresentando uma relação inversa ao que seria esperado, o que pode indicar que os royalties arrecadados foram destinados às despesas correntes.

Ressalte-se que a crise do subprime, representada pela dummy de 2009, mostra em geral um coeficiente negativo e significativo, como esperado. Isso sugere que a redução do ingresso dos royalties em função da baixa produção observada no período impactou negativamente os investimentos públicos realizados pelas municipalidades.

A investigação da relação entre royalties e investimento público foi analisada ainda de forma ponderada pela população dos respectivos municípios, a partir das estimativas da equação (6). A tabela 9 traz os resultados da relação entre os royalties per capita (RPC) e as despesas de capital per capita (DKPC).

Tabela 9

Brasil: estimativas da relação entre DKPC e RPC, na equação (6), para os grupos de municípios, 1999-2011

\begin{tabular}{|ccccc|}
\hline $\begin{array}{c}\text { Despesa de Capital Per } \\
\text { Capita (DKPC) }\end{array}$ & Grupo (1) & Grupo (2) & Grupo (3) & Grupo (4) \\
\cline { 2 - 5 } & Efeitos Fixos & Efeitos Fixos & Efeitos Fixos & Efeitos Aleatórios \\
\hline RRO & $1,7506^{* * *}$ & $0,2271^{* * *}$ & $17,5296^{* * *}$ & 2,9755 \\
& $(0,1422)$ & $(0,0130)$ & $(2,4313)$ & $(2,5216)$ \\
Dummy 2009 & $-3,2530$ & $-14,1770^{* *}$ & $-18,0910^{* * *}$ & $-27,5900^{* * *}$ \\
& $(4,0160)$ & $(5,5815)$ & $(2,7082)$ & $(7,9282)$ \\
№ de Observações & 2332 & 2273 & 2349 & 2265 \\
Procedimento & FGLS & FGLS & FGLS & EA-AR(1) \\
\hline
\end{tabular}

Fonte: Elaboração própria.

Nota: Os números entre parênteses representam, nos estimadores, o valor do desvio-padrão (dp). Significativos a 1\% (***), a 5\% (**) e a $10 \%(*)$.

De acordo com os dados apresentados na tabela 9, os royalties per capita (RPC) afetam positivamente as despesas de capital per capita (DKPC) dos municípios classificados nos Grupos 1, 2 e 3. Esse resultado confirma que a elevação das receitas de royalties por habitante tende a elevar as despesas de capital per capita. Já para os municípios do Grupo 4, não se verificou relação significativa, o que sugere que as despesas de capital (DKPC) não foram afetadas pelo aumento de royalties (RPC). Nas estimações, a crise do subprime, representada pela dummy de 2009, mostra em geral um coeficiente negativo e significativo, confirmando o efeito de depreciação esperado. 
Considerando o conjunto dos resultados, apenas no Grupo 2, onde está a maior arrecadação de royalties petrolíferos, percebe-se um efeito positivo nos investimentos municipais, tanto em termos per capita, como em termos dessa despesa, como proporção da despesa total do município.

\section{Considerações finais}

A situação financeira dos municípios beneficiados pelas receitas de royalties petrolíferos melhorou significativamente, em alguns casos, de acordo com a condição do grupo de municípios, após a promulgação da Lei nº 9.478, de 1997.

Com base nas estimativas realizadas, a partir das equações (5) e (6), foi demonstrado que os municípios dos Grupos 1, 2 e 3 elevaram as despesas de capital per capita (DKPC) com o aumento dos royalties per capita (RPC). Assim, conclui-se que os royalties para esses grupos influenciaram a formação dos gastos per capita em capital no período investigado.

Na perspectiva da proporção das despesas de capital sobre a despesa orçamentária (PDK) em contraste com a proporção das receitas de royalties sobre a receita orçamentária (RRO), ficou evidente que apenas os municípios do Grupo 2 aumentaram a proporção dos gastos de capital em função dos royalties. Para os Grupos 3 e 4, foi constatada uma relação negativa entre essas duas variáveis. Ressalte-se que os resultados mostram um impacto negativo da crise do subprime para os grupos de municípios 2, 3 e 4 .

Os resultados apresentados, portanto, mostram que o ingresso de royalties proporcionou elevação dos gastos com capital na abordagem per capita e fiscal somente no Grupo 2, cujos municípios concentraram mais de $96 \%$ das receitas de royalties no país, tendo recebido cerca de $\mathrm{R} \$ 45,8$ bilhões no período 1999 a 2011. Isso possivelmente ocorre porque nesses municípios o volume arrecadado de royalties tenha um peso para influenciar o investimento público nos municípios que fazem parte deste grupo.

Nessa perspectiva, o objetivo de analisar os royalties petrolíferos à luz das finanças públicas, em especial as despesas de capital, constitui um avanço na medida em que possibilitou a realização de um panorama dos efeitos da aplicação dos royalties sobre as despesas de capital dos entes beneficiados.

Embora seja importante, a evidência não é definitiva, suscitando estudos adicionais para investigar as razões dos resultados nos grupos, inclusive buscando relacioná-los com as atitudes relacionadas com a gestão municipal dos recursos. Abordagens metodológicas adicionais, com utilização de grupos de controle, para verificar o efeito comparativo entre municípios que recebem royalties e aqueles que não recebem, bem como a análise comparativa das elasticidades entre esses municípios, podem representar uma contribuição significativa para futuros trabalhos. 


\section{Referências}

BALTAGI, Badi B. Econometric analysis of panel data. 3. ed. New Delhi, Índia: John Wiley\&Sons, 2005.

BIASOTO JR., Geraldo; AFONSO, José Roberto R. Investimento público no Brasil: propostas para desatar o nó. Novos estudos - CEBRAP [on-line]. n. 77, p. 7-26, 2007.

BRASIL. Lei 9.478, de 06 de agosto de 1997. Dispõe sobre a política energética nacional, as atividades relativas ao monopólio do petróleo, institui Conselho Nacional de Política Energética e a Agência Nacional do Petróleo. Brasília: Lex: Diário Oficial [da República Federativa do Brasil], 1997.

BREGMAN, Daniel. Formação, distribuição e aplicação de royalties de recursos naturais: o caso do petróleo no Brasil. Dissertação (mestrado em economia da indústria e da tecnologia) — Universidade Federal do Rio de Janeiro, Rio de Janeiro, 2007.

BRESSER-PEREIRA, Luiz C. Crescimento e desenvolvimento econômico. Rio de Janeiro: Fundação Getulio Vargas, 2008.

DUARTE, Patrícia C.; LAMOUNIER, Wagner M.; TAKAMATSU, Renata T. Modelos econométricos para dados em painel: aspectos teóricos e exemplos de aplicação à pesquisa em contabilidade e finanças. In: CONGRESSO USP DE CONTROLADORIA E CONTABILIDADE, 7.; CONGRESSO USP DE INICIAÇÃO CIENTÍFICA EM CONTABILIDADE, 4. 2007, São Paulo. Anais... São Paulo, 2007. p. 1-15.

FORBES, Kristin J. A reassessment of the relationship between inequality and growth. The American Economic Review, v. 90, n. 4, p. 869-887, set. 2000.

GODOY, Tarcísio J. M. Influência do nível de investimento do setor público sobre o crescimento econômico e a produtividade total dos fatores. Dissertação (mestrado) - Universidade de Brasília, Brasília, 2011.

GREENE, William H. Econometric Analysis. 4. ed. Nova Jersey: Prentice-Hall, 2000.

HARTWICK, John M. Intergeneration equity and the investing of rents from exhaustible resources. The American Economic Review, v. 67, n. 5, p. 972-974, dez. 1977.

HOTELLING, Harold. The economics of exhaustible resources. The Journal of Political Economy, v. 39, n. 2, p. 137-75, abr. 1931.

MALTHUS, Thomas R. An inquiry into the nature and progress of rent, and the principles by which it is regulated. Londres: Pickering\&Chatto, 1986.

MONTES, Gabriel C.; REIS, Artur F. Investimento público em infraestrutura no período pós-privatizações. Economia e Sociedade, v. 20, n. 1, p. 167-194, 2011.

NOGUEIRA, Dart C. F.; SANTANA, José R. Royalties da indústria do petróleo: contribuição efetiva ao desenvolvimento sustentável nos municípios sergipanos? Revista Econômica do Nordeste, v. 39, n. 3, p. 445- 465, jul./set. 2008.

NOGUEIRA, Lauro C. B.; MENEZES, Tatiana A. M. Os impactos dos royalties do petróleo e gás natural sobre o PIB per capita, índices de pobreza e desigualdades. In: Encontro Regional de Economia, XVI, 2011, Fortaleza.

PERES, Marco A. F. Os efeitos dinâmicos da política fiscal sobre a atividade econômica: um estudo para o caso brasileiro. Dissertação (mestrado) — Universidade de Brasília, Brasília, 2006. 
POSTALI, Fernando A. S. Petroleum royalties and regional development in Brazil: the economic growth of recipient towns. Resources Policy, v. 34, n. 4, p. 205-213, dez. 2009.

POSTALI, Fernando A. S. Renda mineral, divisão de riscos e benefícios governamentais na exploração de petróleo no Brasil. Rio de Janeiro: BNDES, 2002.

POSTALI, Fernando A. S.; NISHIJIMA, Marislei. O retorno social dos royalties do petróleo nos municípios brasileiros. In: ENCONTRO NACIONAL DE ECONOMIA ANPEC — ASSOCIAÇÃO DE CENTROS DE PÓS-GRADUAÇÃO EM ECONOMIA, XXXVI, 2008, Salvador.

RICARDO, David. Princípios de economia política e tributação. São Paulo: Abril Cultural, 1996 [1. ed. 1817].

RODRIGUES, Francisco; SACHS, Jeffrey D. Why do resource abundant economies grow more slowly? A new explanation and an application to Venezuela. Journal of Economic Growth, v. 4, n. 3, p. 277-303, set. 2004.

SACHS, Jeffrey D.; WARNER, Andrew M. The big push, natural resource booms and growth. Journal of Development Economics, v. 59, n. 2, p. 43-76. jun. 1999.

SANTANA, José R.; GARCIA, Fernando; SOUZA, Rogério. Efeitos da infraestrutura sobre o crescimento e sobre a produtividade. In: ENCONTRO REGIONAL DE ECONOMIA DA ANPEC — FÓRUM BNB DE DESENVOLVIMENTO, X, 2005, Fortaleza. Anais... Fortaleza: BNB; Etene, 2005.

SERRA, Rodrigo. Contribuição para o debate acerca da distribuição dos royalties petrolíferos no Brasil. Tese (doutorado em economia) — Universidade de Campinas, Campinas, 2005.

STN. Secretaria do Tesouro Nacional. Finanças do Brasil — Finbra. Disponível em: < hwww.tesouro. fazenda.gov.br> Acesso em: 10 fev. 2012.

UCAM. Universidade Candido Mendes. Sistema info royalties. Disponível em: <www.inforoyalties. ucam-campos.br> Acesso em: 18 jan. 2012.

VEIGA, José E. O prelúdio do desenvolvimento sustentável. In: OLIVA, Pedro Mercadante. Economia brasileira: perspectiva do desenvolvimento. São Paulo: FEA-USP; Centro Acadêmico Visconde de Cairu, 2005.

WOOLDRIDGE, Jeffrey M. Introductory econometrics: a modern approach. 5. ed. Mason, OH: SouthWestern, 2013.

Diego Araujo Reis é mestre em desenvolvimento regional e gestão de empreendimentos locais pela Universidade Federal de Sergipe (UFS). Professor substituto do Departamento de Economia da UFS. E-mail: diegoaraujoreis@hotmail.com.

José Ricardo Santana é doutor em economia de empresas pela Fundação Getulio Vargas (FGV/SP). Professor associado do Departamento de Economia da Universidade Federal de Sergipe (UFS). E-mail: jrsantana.ufs@gmail.com. 